\title{
Psychological readiness for the risk of innovative activities of teachers
}

\author{
Tatiana Mikheeva ${ }^{1, *}$ and Marina Elagina ${ }^{1}$ \\ ${ }^{1}$ Don State Technical University, 344003, Gagarin sq., 1, Rostov on Don, Russia
}

\begin{abstract}
The article is devoted to the description of the risks of innovation, the characteristics of approaches and the principles of their analysis. Particular attention is paid to the definitions of risk as a term of sociology and psychology. The structure and content of the psychological readiness of the subjects of the process to the justified risk of innovation are determined.
\end{abstract}

\section{Introduction}

Risks of innovation occupy a special place among scientific research. The need to study the psychological content and personal characteristics that determine the ability to successfully perform professional activities in conditions of risk, as well as the readiness for innovative risk as one of the factors predisposing to its manifestation, are determined by the problem of ensuring a high level of professional efficiency of the subjects of the educational process - teachers.

Fundamental and applied research aimed at studying various aspects of risk is reflected in research

- behavior of a person in risky situations;

- the influence of motivation on decision-making and human behavior under risk conditions [Kornilova, 2003]

- readiness for risk in teaching [Khabibulin., 2008].

\section{Materials and Methods}

The problem of analyzing the process of reforming school education is solved. Theoretical research methods and elements of the group associative method were used.

\section{Results}

\footnotetext{
* Corresponding author: mitata.m@yandex.ru
} 
The teacher's readiness for innovative activities in the aspect of overcoming risks, as well as the issues of psychological development of the professional qualities of teachers are actively studied.

Unfortunately, the modern practice of implementing educational innovations is replete with manifestations of haste and lack of thoughtfulness, which is manifested

- in violation and balance of traditions and innovations in the process of reforming the education system;

- in the ignore and possible negative consequences of ongoing innovation and the weak development of preventive practices;

- in the ambiguity and results of many of the ongoing educational innovations.

Analysis of the world practice of innovations shows that there are problems, resistance to changes in specific educational organizations, there are problems in retraining and professionals. Despite the relevance, this topic is not sufficiently researched from the point of view of psychology.

Purposeful changes in the education system are due to the presence of psychological readiness for the risk of innovative activities of school teachers.

According to scientists, modern society is risky, regardless of our attitude to it. Analyzing the mechanics of risk production proper, E Giddens emphasized that the modern world is structured mainly by risks created by man. These risks have a number of distinctive features.

First, modern risks are due to globalization in terms of their range (nuclear war).

Second, the globalization of risks, in turn, is a function of an increasing number of interdependent events (for example, the international division of labor).

Third, the modern world is a world of "institutionalized risk environments", for example, the investment market, on the state of which the well-being of millions of people around the world depends. The production of risks is dynamic: risk awareness is a risk, since "gaps" in cognitive processes cannot, as before, be converted into "reliability" of religious or magical knowledge.

Fourth, modern society is oversaturated with knowledge about risks, which in itself is a problem and a kind of risk.

Fifth, E. Giddens (as well as N. Luhmann) pointed out the limitations of expert knowledge as a tool and elimination of risks of societal systems.

E. Giddens introduces an important thesis: risk creates its own environments that affect huge masses of individuals (a good example is large cities). He defines safety in such an environment as a specific set of minimized hazards. The subjective experience of safety in a risk environment is usually balanced between trust and the level of acceptable risk. The analysis of the risk distribution of activities under the current state of affairs and knowledge constitutes a risk profile, which creates a risk-generating environment [Giddens, 2004].

In modern scientific literature, with all the diversity of approaches, two major directions can be distinguished in the interpretation of risk as a phenomenon. According to a realistic Nome approach, the risk is interpreted in scientific and technical terms. This trend goes back to the cognitive sciences based on psychology and is practiced by the disciplines of engineering, economics, statistics, psychology and epidemiology. The starting point of this approach is the concept of danger (harm), as well as the statement about the possibility of calculating the time of its occurrence and calculating the consequences. In this case, risk is defined as "the product of the likelihood of the hazard and the severity (scale) of its consequences" [Bradbury, 1989, p. 382].

The second direction of scientific thought is the emergence of another powerful vector of risk analysis - sociocultural. It focuses on the social and cultural contexts within which 
risk is perceived and discussed by people. This direction arose on the basis of such humanitarian disciplines as philosophy, cultural anthropology, sociology.

Historians of the sociology of risk conditionally distinguish three approaches within the framework of the second direction:

- cultural and symbolic, developed by M. Douglas and her colleagues,

- the theory of "risk society" presented by W. Beck and E. Giddens,

- "calculative rationality", based on the work of M. Foucault.

The first approach focuses on the problems of the relationship between the "Personality" and the "Other" with a particular interest in how the human body is used symbolically and metaphorically in discourse and practices around the problem of risk.

The second focuses on the macro-social changes generated by the production of risks during the transition to high modernization: these are the processes of reflexive modernization, criticism of the consequences of the previous stage of modernism and individualism, the consequences of the destruction of traditional values and norms.

Proponents of the third approach have little interest in "what the risk really is" because they believe that "the truth about risk" is constructed through human discourse, strategies, practices, and institutions. They also explore how different concepts of risk generate specific behavioral norms that can be used to motivate individuals to freely participate in self-organizing processes in risky situations [Lupton,1999, p. 25].

\section{Discussion}

Psychological aspects of human behavior in a risk situation became the focus of attention of psychologists at the beginning of the formation of applied psychology, namely in the 1920s. XX century. The inclination to take risks was considered as a personal property that acted as a professionally important quality in dangerous professions or as an undesirable quality, a contraindication in professions where caution and prudence must be exercised. As noted by M.A. Kotik in the book "Psychology and Safety", the propensity to take risks was assessed using situational-behavioral methods or survey methods involving self-assessment and self-report [Kotik, 1989]. In the 70s-80s. XX century. risk appetite has become a subject of study in economic psychology.

However, the frontal study of the phenomenon of risk began only in the middle of the 20th century, with the formation of an idea of the probabilistic nature of natural and social trends, when the mathematical apparatus corresponding to the solution of real needs was being worked out, and statistical data were accumulated. The starting point for the formation of risk theory should be considered the end of the $60 \mathrm{~s}$ of the XX century. Observations of the social consequences of the development of the scientific and technological revolution in the United States led to the appearance of works devoted to the problems of the ratio of the positive and negative consequences of technological risks.

The 21 st century introduces the factor of combining risks of various origins and requires the development of integrated approaches to their analysis. At the same time, there is a tendency towards differentiation of sciences and research areas, striving for knowledge of "their own" subject areas in relation to risks. 


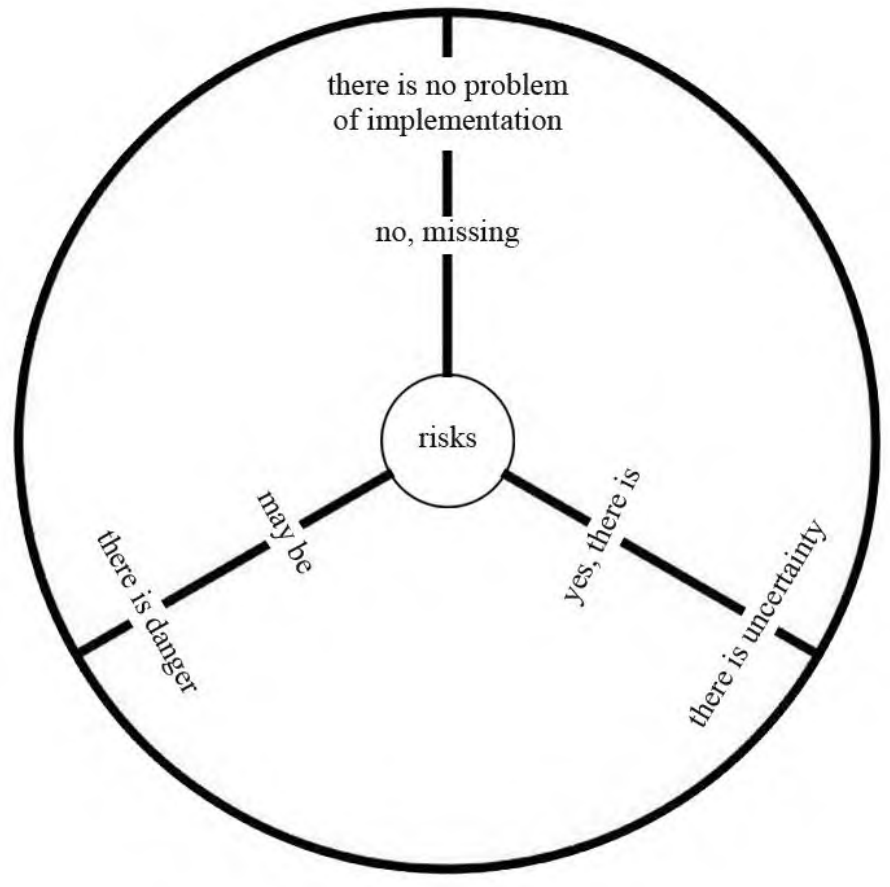

Fig.1. Existence of risks in human life

Risk is one of the keys, most important elements of any human activity. Understanding what risk is very important. The experience of mankind testifies that those who know how to take risks in time are a big winner. For example, decisive politicians, brave commanders, fearless entrepreneurs and engineers, finally, examples from their own lives, when "the courage of the city takes."

At present, researchers recognize that risks do not exist if there is no problem of their implementation and solution. In fact, we are talking about the activity of the subject, which acts in conditions of uncertainty. An interesting position is N. Luhmann, who, defining risk, distinguishes it from danger. He believes: if the causes of damage are associated with the objective processes of the world around a person, then he means danger. Risk can be discussed when a decision is made, without which the damage could not have occurred. Moreover, the decision to decrease the risk of becoming a risk s [Luhmann 1997].

It follows from this that risk is a consequence generated by an uncertain environment, when both a positive result (a favorable outcome) and a negative one (an unfavorable result associated with significant losses) are possible. Even more specifically, risk can be interpreted as a measure of discrepancy between different possible results of decisions made and implemented. Strictly speaking, risk can only take place where there is a choice. In the absence of real alternatives, only one decision can be made. In this case, it seems that the decision maker - the subject of risk - does not risk anything. But in fact, he runs the risk of himself being in this uncontested situation: the lack of alternatives and choice means that there is no possibility of high profits.

Therefore, the expansion of the field of real alternatives does not always lead to an increase in risk along with an increase in the responsibility of a decision-maker in conditions of uncertainty. 
In modern research, there are three main interpretations of risk. In the first of them, risk is defined as the activity (actions) of an individual aimed at obtaining the desired result by avoiding danger, making a choice with the hope of success in a situation with a possible unfavorable outcome, receiving a reward, asserting in the eyes of other people or selfassertion, as an attempt to expand boundaries own capabilities, achievement of the set goal or realization of the desire to obtain thrills. The result of such activity is uncertain and may be unfavorable, i.e. be accompanied by loss, damage, injury.

In the second interpretation, risk is understood as a predictive assessment category, a measure of an unfavorable outcome, which is determined by the probability and size of a possible loss, and also reflects the balance between luck and failure and is formed at the stage of planning and organizing an action.

In the third view, risk is considered as a characteristic of a situation or action, characterized by the presence of danger or uncertainty and associated with the need to make a decision, to make a choice from a number of possible alternatives, where at least one of the decisions may end in an unfavorable outcome.

What the above concepts have in common is that they unanimously regard a risk situation as an assessment situation. Risk expresses "a predictive estimate of the likelihood of an unfavorable outcome of an evolving (not yet finished) situation. Risk is not a descriptive (attributive) characteristic of a situation, but an evaluative category, inextricably linked with a person's action, his assessment - self-assessment" [Solntseva, 1999, p. 22].

Psychological readiness for a reasonable risk of innovative activity includes:

- the ability to take responsibility for the results of innovative activities;

- understanding the process, mechanisms and results of ongoing innovations;

- the ability to overcome psychological barriers arising in the course of innovation;

- skills of forecasting, modeling and decision-making in conditions of uncertainty that give rise to risks.

The criteria for the psychological readiness of school teachers to the risk of innovation are:

- a high level of "risk readiness" combined with a high level of "rationality";

- high meaningfulness of life and the presence of a purpose in life;

- a high level of vitality and psychological well-being;

-the ability to self-regulation (programming, modeling, independence, flexibility);

- taking responsibility for oneself;

- achievement motivation;

- the established system of self-development.

\section{Conclusion}

The presence of psychological barriers to the innovation activity of the subjects of the educational process is determined by the unpreparedness (low readiness) for risks, the unclear idea of teachers about educational innovations and their role in them, the lack of personal readiness to participate in innovative processes, the unformed values of selfrealization and self-development.

Psychological readiness for the risk of innovative activity of the subjects of the educational process in schools is a dynamic reserve for the implementation of various vectors of innovative development of education and a factor that determines a conscious rational attitude to risks and a conscious choice when making decisions in situations of uncertainty. Psychological readiness for innovative risk is an integral systemic characteristic of a person, which has a certain level of formation of personal potential [Elagina, 2011]. 


\section{References}

1. Ju. V. Belova, A. A. Mirolyubova, Risks of innovative activity of the Higher educational institution. Sbornik nauchnih trudov vuzov Rossii "Problemy ekonomiki, finansov I upravleniya proizvodstvom”, 41, 53-57 ID: 30711445 (2017)

2. J. Bradbury, The Policy Implications of Different Concepts of Risk. Science, Technology \& Human Values, 14(4), 380-399 (2017)

3. G. Eichsteller, S. Holthoff, Risk Competence Towards a Pedagogic Conceptualisation of Risk. ThemPra Social Pedagogy C.I.C. http://www.thempra.org.uk/downloads/risk.pdf (Last accessed 21.07.2020)

4. M. Yu. Elagina, Psychological readiness to the risks of innovative activity of heads of general education institutions: PhD diss., Psychological Sciences, 170 (Rostov-on-Don, 2011)

5. A. Giddens, The Elusive World: How Globalization Changes Our Lives. Moscow Whole World, 120, 119-120 (2004)

6. E. R. Khabibulin, Readiness to risk as a factor of effective pedagogical activity in situations of uncertainty: PhD diss., 141 (Psychological Sciences, Moscow, 2008)

7. T. V. Kornilova, Psychology of risk and decision making: textbook. manual for universities, 286 (Moscow, Aspect Pres, 2003)

8. M. A. Kotik, Psychology and Security, 448 (Tallinn: Valgus, 1989)

9. N. Luhmann, Gesellschaft der Gesellschaft. Kapitel5 - Selbstbeschreibungen. Zweiter Teilband, 866-1150, (Frankfurt am Main, 1997)

10. D. Lupton, Risk [Text] L., 184 (NY: Routledge, 1999)

11. T. B. Mikheeva, E. V. Murugova, Management of educational and cognitive activity of students within the framework of psychological and pedagogical aspect, Shs web of conferences, 70, 07003 (2019) doi: https://doi.org/10.1051/shsconf/20197007003

12. E. G. Popkova, A. A. Sozinova, O. Y. Grechenkova, V. I. Menshchikova, Deficiencies in the legislative support of innovative activities in contemporary Russia and ways of addressing them. Russian journal of criminology (2018) https://www.scopus.com/inward/record.url?eid=2-s2.0-85053835683\&partner (Last accessed 26.07.2020)

13. T. I. Rudneva, Pedagogical risks in education - new social realit. Vestnik Orenburgskogo gosudarstvennogo universiteta. 4(216), 71-75 (2018)

14. G. N. Solntseva, Psychological content of the concept of "risk". Bulletin of Moscow State University. Ser. 14. Psychology, 2, 14-22 (1999)

15. M. B. Tiven, E. R. Fuchs, A. Bazari, A. MacQuarrie, Evaluating Global Digital Education: Student Outcomes Framework. New York, NY: Bloomberg Philanthropies and the Organisation for Economic Co-operation and Development (2018) https://www.oecd.org/pisa/Evaluating-Global-Digital-Education-Student-OutcomesFramework.pdf (Last accessed 26.07.2020)

16. V. V. Ulitko, It informal education of the teacher as a condition of achievement of professional. Azimuth of Scientific Research: Pedagogy and Psychology, 1(26), 265270 (2019) DOI: 10.26140/anip-2019-0801-0066 